\title{
New Attachment Achieved by Guided Tissue Regeneration in Beagle Dogs
}

\author{
R. G. Caffesse, ${ }^{\star}$ B. A. Smith, $†$ W. A. Castellił and C. E. Nasjleti§
}

Accepted for publication 23 February 1988

\begin{abstract}
THIS STUDY TESTED THE EFFECTS of using a Gore-Tex periodontal material on new connective tissue attachment in beagle dogs with natural periodontitis. Seven female beagle dogs with advanced periodontitis were selected and given thorough root debridement. Under general anesthesia four weeks later, mucoperiosteal flaps were raised involving all mandibular premolars and first molars. Gore-Tex periodontal material was adapted to all premolars, and the flaps were sutured tightly, keeping the material covered. The first molars acted as controls, receiving only surgery. Some material was removed in one month, while other materials were removed eight to 10 weeks after surgery. All dogs were sacrificed at three months. After processing, descriptive histology and histometrics were carried out, evaluating new connective tissue attachment, bone response and epithelial downgrowth.

Results were statistically analyzed, using paired $t$ tests. They showed new connective tissue attachment with cementum deposition in areas where the material was used. Also, the epithelial downgrowth was reduced in these areas. In the controls, minimal connective tissue attachment was found, with the area healing by a long junctional epithelium. Statistical analysis showed significant differences $(P<0.05)$ favoring experimental areas both in the increase of new connective tissue attachment and in the decrease of epithelial downgrowth. No differences were found between areas where the material was removed in one month or left longer in place. No difference in bone response was found. Gore-Tex material was effective in blocking gingival epithelial downgrowth and connective tissue proliferation, promoting new attachment according to the principle of "guided tissue regeneration."
\end{abstract}

Two approaches have been stressed to promote new attachment after periodontal therapy: (1) modifying the exposed root surface to provide a better substrate for cell attachment and differentiation ${ }^{1}$ and (2) repopulating the exposed root surface with cells from the remaining periodontal ligament, on the theory that progenitor cells arising from the periodontal ligament are the only ones with the potential to differentiate into cementoblasts. This coronal periodontal cell proliferation implies that the proliferation of other tissues, specifically epithelial and gingival connective tissues, must

*Formerly, Professor and Chairman, Department of Periodontics, The University of Michigan School of Dentistry, Ann Arbor, MI 48109. Presently, Professor and Chairman, Department of Periodontics, The University of Texas Health Scienice Center, Dental Branch, Houston, TX 77030.

†Associate Professor, Department of Periodontics, The University of Michigan School of Dentistry.

$\ddagger$ Professor of Anatomy, Medical School, The University of Michigan, Ann Arbor, MI 48109.

§Formerly Dental Research Program, V.A. Medical Center, Ann Arbor, MI 48109. Presently, Senior Research Associate, Department of Periodontics, The University of Texas Health Service Center. be blocked. That is the basis for what is known today as "guided tissue regeneration." 2

Based on previous studies in their laboratory, ${ }^{3-5} \mathrm{Ny}-$ man, Karring, Lindhe and coworkers suggested such an approach in $1982 .{ }^{6}$ Since then, clinical and histologic studies by them and others have given credence to the concept that if periodontal proliferation is promoted, new attachment to a previously exposed root surface can be achieved..$^{7-12}$

Different materials have been used to block epithelium and gingival connective tissue. ${ }^{7,8,11,12}$ The present study tested the effects of Gore-Tex periodontal material on new connective tissue attachment in beagle dogs with natural periodontitis.

\section{MATERIALS AND METHODS}

Seven adult female beagle dogs having natural periodontitis and purchased from a closed beagle colony were used. They presented with advanced periodontitis involving all the mandibular premolars and first molars. After being housed for two weeks, the dogs were sedated with an intramuscular injection of Ketamine $\mathrm{HCl}(25$ $\mathrm{mg} / \mathrm{ml}$ ), and the teeth were thoroughly scaled and root 
planed. Thereafter, oral hygiene was maintained by daily brushings and topical application of chlorhexidine, and rubber cup prophylaxes once a week.

Four weeks after root instrumentation, the animals were anesthetized using sodium pentobarbital I.V. (30 $\mathrm{mg} / \mathrm{ml}$ ). A mucoperiosteal flap was raised using a reverse bevel scalloped incision on all mandibular bicuspids and first molars. After removal of granulation tissue and complete root instrumentation, a notch was placed in the roots at the level of the alveolar crest using a No. $1 / 2$ round bur.

An expanded Teflon membrane (Gore-Tex ${ }^{\circledast}$ periodontal material) was adapted, in the fashion of a rubber dam, to each one of the premolars (Figs. 1A and 1B). Such membranes are nonresorbable and are made up of a margin that has an open microstructure, supposedly to inhibit epithelial migration, and an apron made out of an occlusive material designed to stop the proliferation of gingival connective tissue. The margin adapted closely to the neck of the teeth while the apron extended to cover the alveolar crest. The flaps were positioned slightly coronally and sutured. The molars acting as controls, were treated by surgery alone. Although the discrepancy in size between molars and premolars was recognized, the amount of bone loss was similar around all teeth and consequently changes in linear measurements should not have been affected. Furthermore, the shape and size of the membranes available at that time precluded their use on molar teeth.

Membranes in one quadrant were removed in one month, while those in the contralateral quadrant were maintained for a longer time, being removed between eight and 10 weeks postoperatively. When marginal exposure of the membrane was observed, it was trimmed to the level of the free gingival margin and left in place. To remove the membranes, a split thickness flap procedure was performed, and the tissue was sutured back after membrane retrieval.

All animals were sacrificed by exsanguination three months after membrane placement. The heads were fixed with formalin using perfusion prior to decapitation. After fixation the blocks including the experimental and control teeth were decalcified in EDTA, sectioned at 5- to $6-\mu \mathrm{m}$ intervals, mounted and stained with hematoxylin and eosin, Mallory's trichrome, and silver impregnation.

Descriptive histology and histometric analysis were carried out. Linear measurements were recorded on experimental and control teeth from the apical end of the notch as follows:

1. The distance from the radicular notch to the coronal level of the connective tissue.

2. The distance from the radicular notch to the alveolar crest.

3. The distance from the gingival margin to the apical end of the junctional epithelium.

Approximately eight step serial sections were measured per tooth. Mean values of these sections for each dog were obtained for the control teeth, for teeth where the membrane was maintained for 30 days, and for teeth where the membrane was kept for more than 30 days. Thus, three measurements were available for each dog and these measurements were analyzed using paired $t$ tests $(N=7)$ to see whether different treatments had any effect on any of the histometric parameters tested.

\section{RESULTS}

Healing progressed uneventfully and was clinically considered complete in similar time periods for controls and experimental areas. If the margin of a membrane started to be clinically exposed, it was trimmed to the level of the free gingival margin with a pair of scissors. In these instances a brilliant red granulation tissue growing from underneath the membrane was observed attached to the roots.

\section{Histologic Description}

Control areas showed marginal healing to the teeth by a long junctional epithelium, with minimal connec-
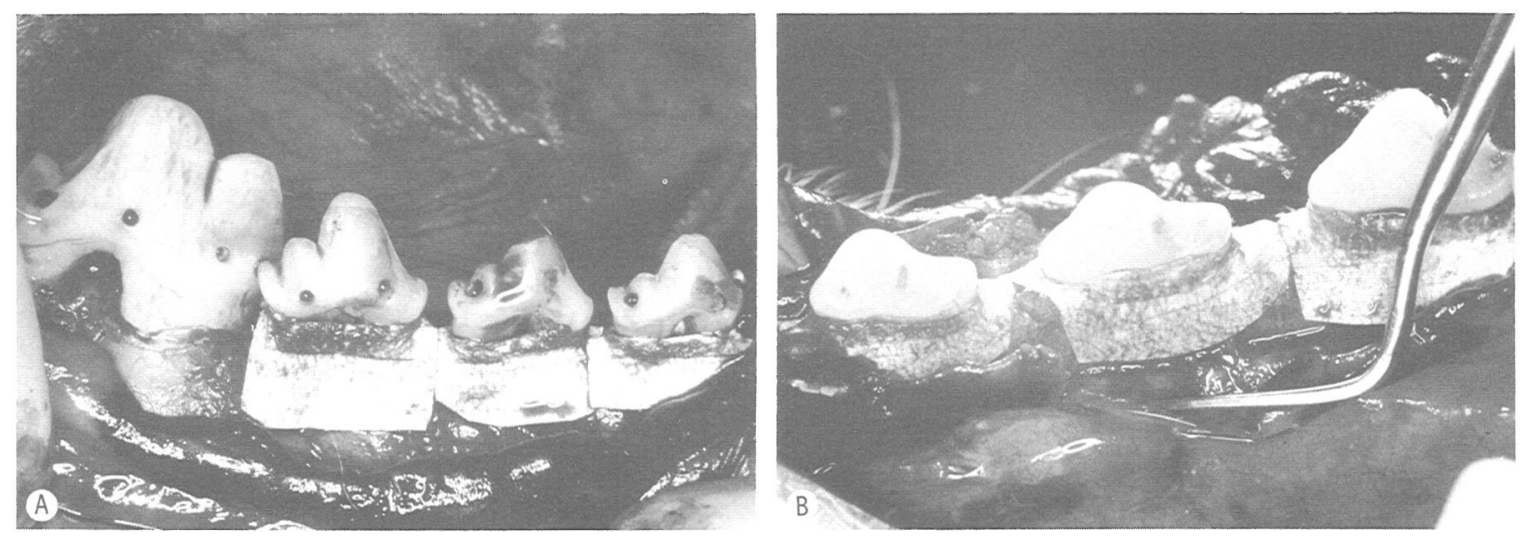

Figure 1. A. Gore-Tex membranes applied to $P_{2}, P_{3}$, and $P_{4}$. The collar adapts to the teeth while the apron covers the alveolar crest. B. Lingual view showing membranes in place. 
tive tissue attachment. The junctional epithelium reached the tooth in most instances at the level of the notch. Minimal bone repair was seen (Fig. 2A).

Conversely, the experimental areas showed new cementum formation in the notch as well as coronal to the notch. It was present both on dentin and old cementum. The alveolar crest also increased in height coronal to the notch in some areas; however, in other areas bone resorption had taken place. Insertion of periodontal ligament fibers into the newly deposited cementum was clearly visible (Figs. $2 \mathrm{~B}-5$ ).

The proliferation of the junctional epithelium was halted, with most of the marginal seals being established by a short junctional epithelium.

\section{Histometric Evaluation}

Table 1 presents the results of the histometric evaluation. Where Gore-Tex membranes were used, the amount of connective tissue attachment, which corresponded to new cementum apposition, was significantly greater than in controls. Likewise, the epithelial downgrowth was substantially reduced. No differences were found between areas where the membrane was removed in 30 days and those where it was left in place for a longer period. There was no difference in the response to treatment as far as the level of the alveolar crest was concerned. However, for all groups a wide variability in results was found for all parameters. Figure 6 represents the results achieved regarding new connective tissue attachment and epithelial downgrowth. Figure 7

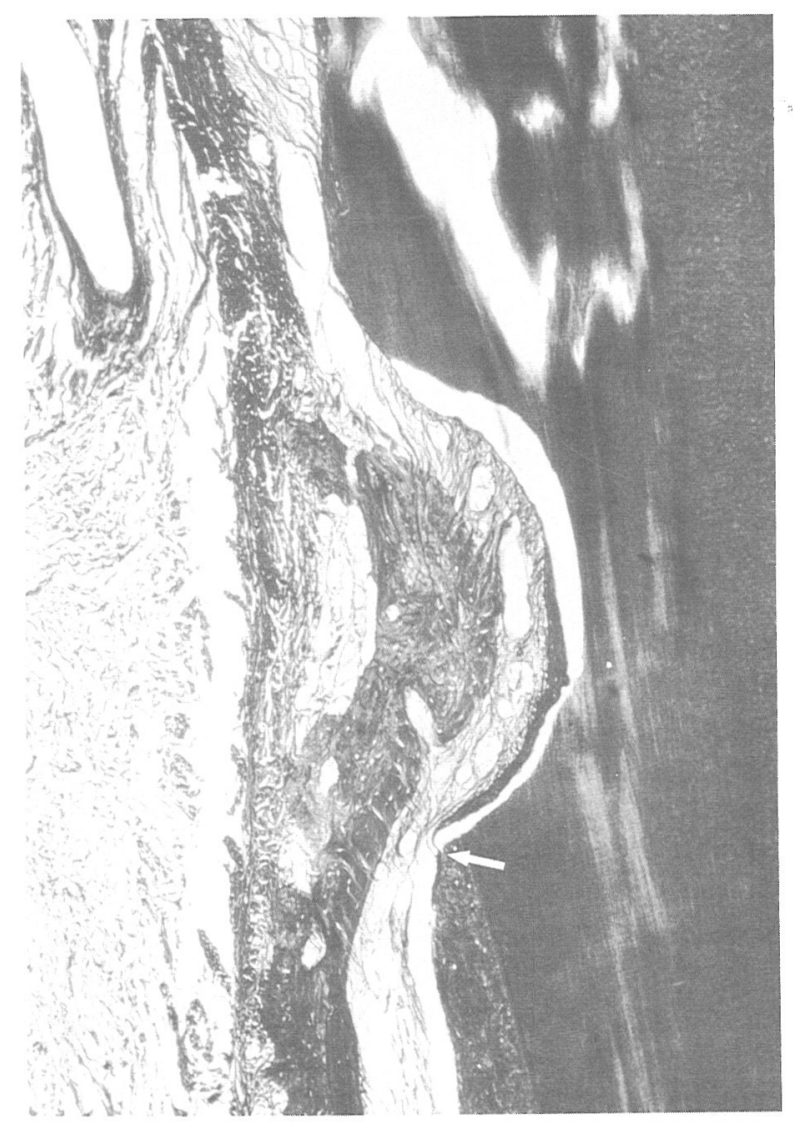

Figure 3. Area similar to Figure $2 B$, as observed with silver impregnation stain. Functional arrangement of the periodontal ligament is evident. Arrow indicates apical end of the notch (magnification $\times 35$ ).
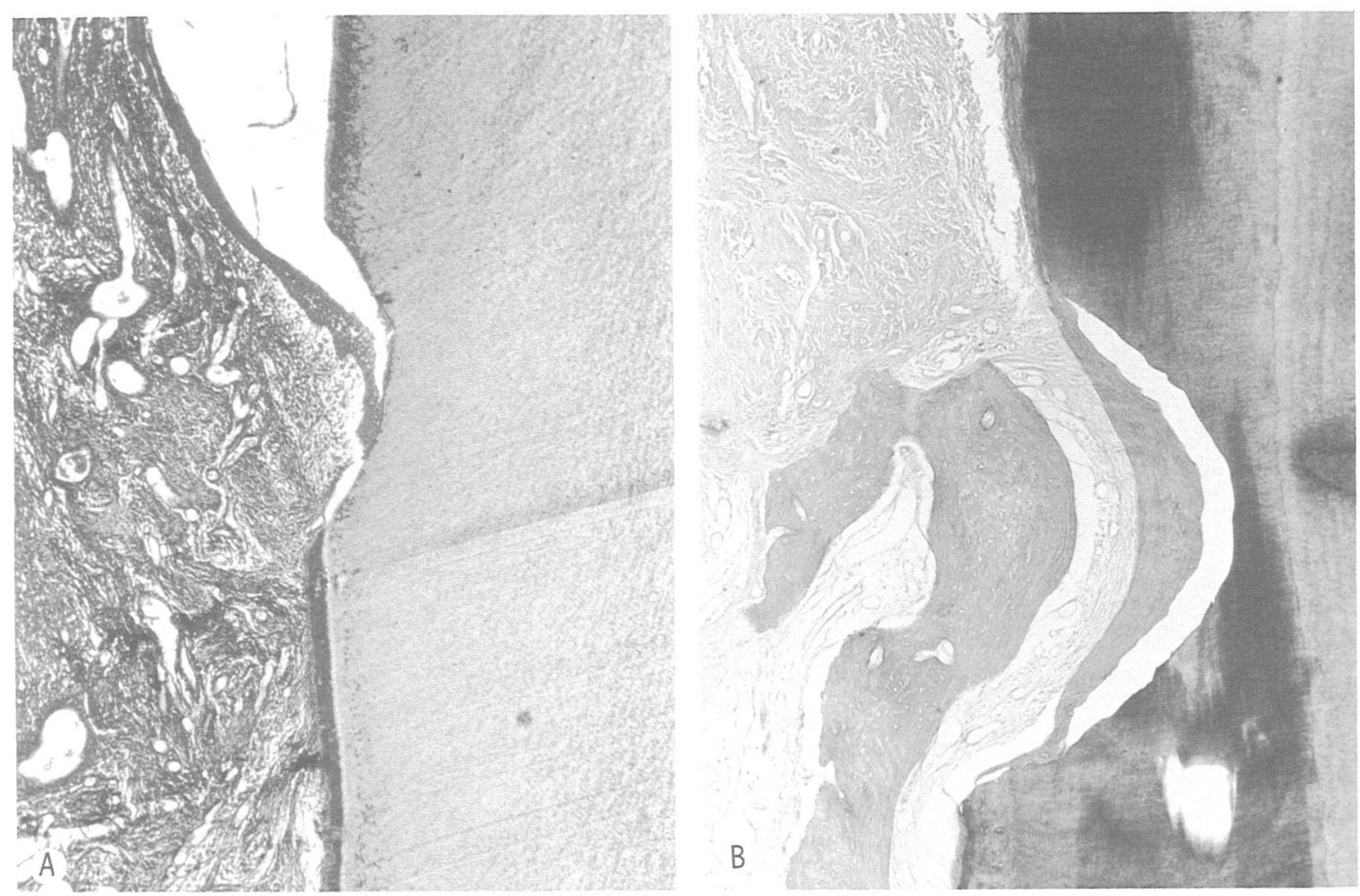

Figure 2. A. Control area. A long junctional epithelium extends almost to apical end of the notch (magnification $\times 25)$. B. Experimental area showing new cementum, bone, and connective tissue fiber arrangement (magnification $\times 35$ ). 


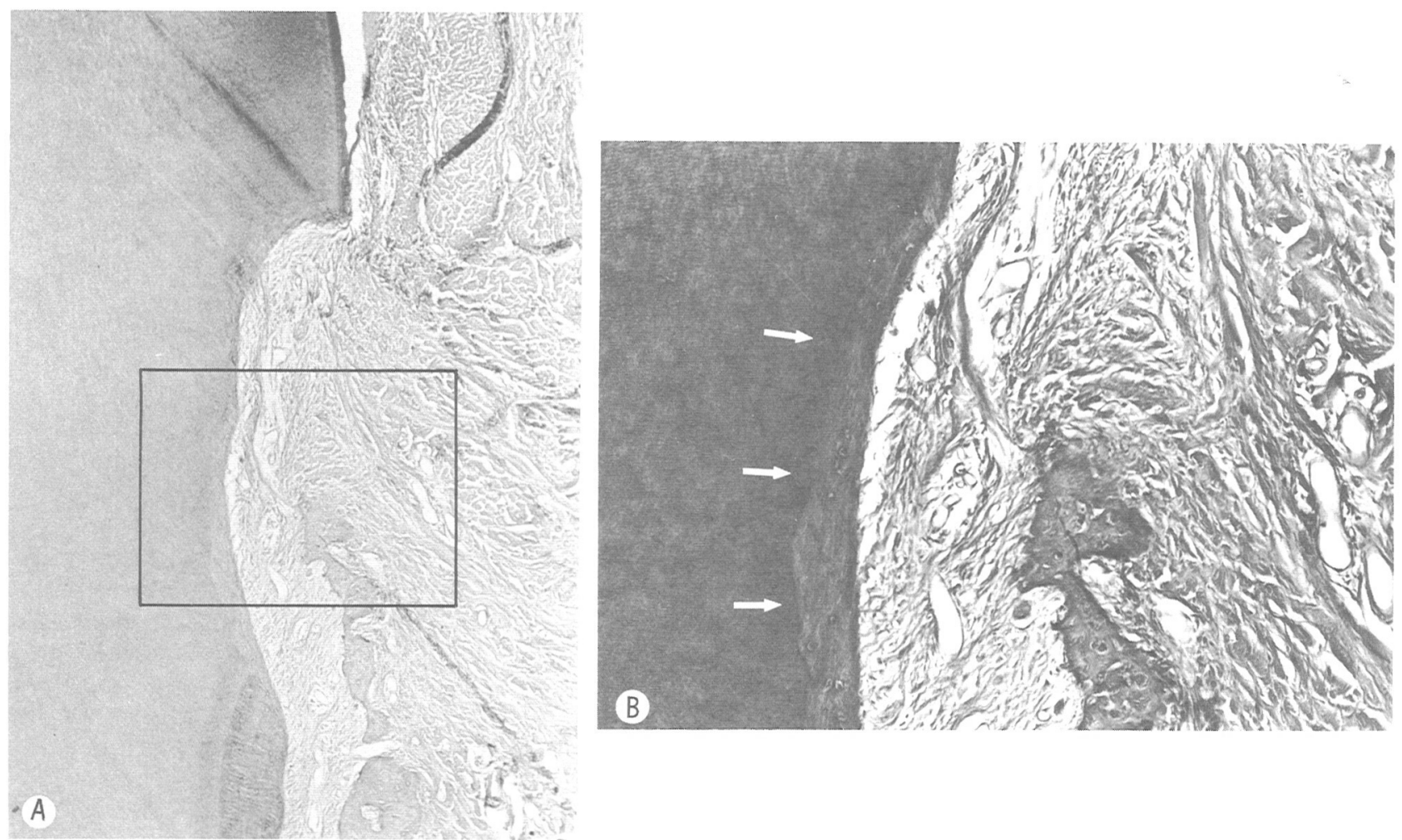

Figure 4. A. Regeneration after membrane placement. New bone, cementum, and periodontal ligament are evident (magnification $\times 35$ ). B. Higher magnification of framed area in Figure 5 showing new cementum deposition (arrows).

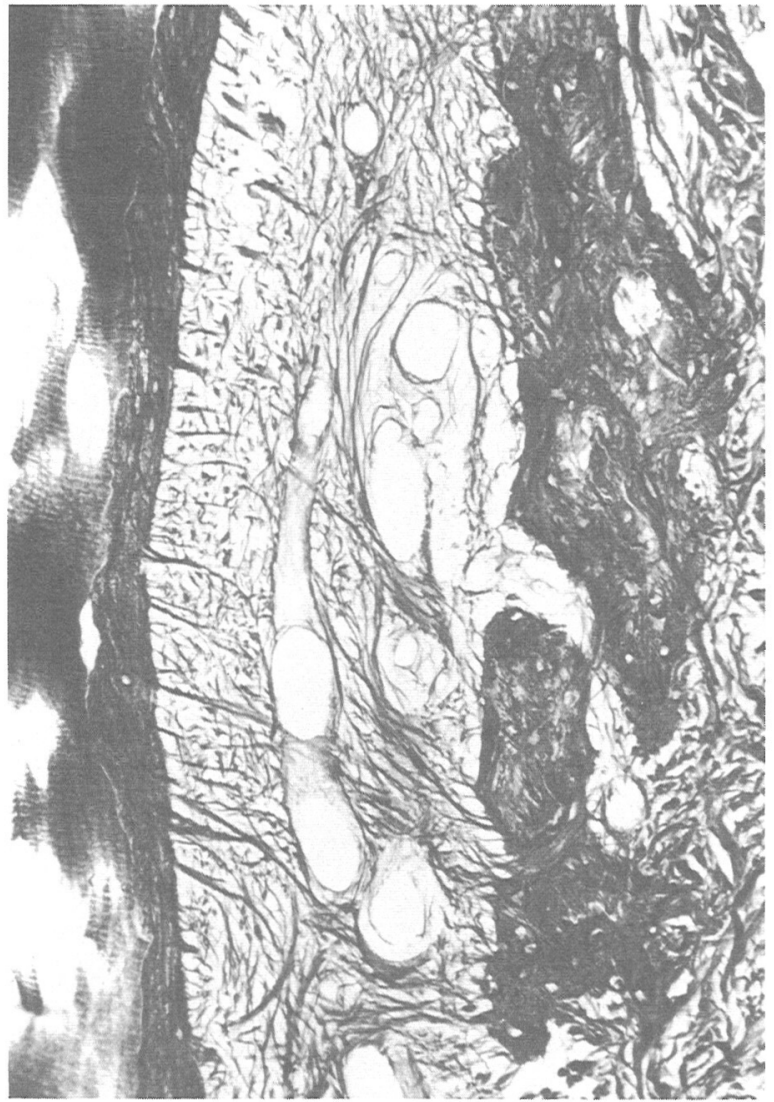

Figure 5. Higher magnification of area corresponding to Figure 5 stained with silver impregnation. Attachment of connective tissue fibers to new cementum and new bone is apparent (magnification $\times$ 100). shows the percentage of new attachment achieved in each group.

\section{DISCUSSION}

The present study supports the effectiveness of the Gore-Tex periodontal material in blocking gingival epithelial downgrowth and connective tissue proliferation, thus promoting new attachment by allowing proliferation from the periodontal membrane. This agrees with previous reports supporting the benefits of guided tissue regeneration. ${ }^{2,6-9,11,12}$ Through a series of studies, it has been postulated that, the primary source of cells that repopulate the root will determine the result..$^{3-5,8-10}$ If epithelium is allowed to migrate, a long junctional epithelium will be established. If proliferation from the gingival connective tissue is allowed, resorption of the root may occur. If the response comes from the bone, the result may be ankylosis. In essence, the only possibility for regeneration appears to come from the periodontal ligament acting as a source for cell proliferation, which was the case in this study. It must be emphasized, however, that use of the membrane does not preclude the possibility that bone cells will repopulate the root. Apparently the speed of the periodontal ligament cells in repopulating the root seems to be greater than that of the bone cells, and cellular proliferation studies seem to confirm this assumption. ${ }^{13}$

The regeneration of the periodontal attachment associated with deposition of new cementum on the root is followed by new bone apposition at the alveolar crest. 
Table 1

Linear Histometrics Comparing Control and Experimental Areas in B-L Sections After 3 Months of Healing (in mm) in Beagle Dogs*

\begin{tabular}{|c|c|c|c|c|c|c|}
\hline & \multicolumn{2}{|c|}{$\begin{array}{c}\text { Notch-Junctional } \\
\text { Epithelium }\end{array}$} & \multicolumn{2}{|c|}{ Notch-Bone } & \multicolumn{2}{|c|}{$\begin{array}{c}\text { Gingival margin- } \\
\text { Junctional } \\
\text { Epithelium }\end{array}$} \\
\hline & Range & $\bar{X}$ & Range & $\bar{X}$ & Range & $\overline{\mathrm{X}}$ \\
\hline Control & $\begin{array}{l}0.07 \\
0.99\end{array}$ & 0.57 & $\begin{array}{r}-1.15 \\
0.69\end{array}$ & -0.39 & $\begin{array}{l}1.16 \\
2.56\end{array}$ & 1.97 \\
\hline $\begin{array}{l}\text { Gore-Tex } \\
<30 \text { days }\end{array}$ & $\begin{array}{l}0.00 \\
1.93\end{array}$ & 1.09 & $\begin{array}{r}-1.62 \\
0.51\end{array}$ & -0.87 & $\begin{array}{l}1.00 \\
2.29\end{array}$ & 1.59 \\
\hline $\begin{array}{l}\text { Gore-Tex } \\
>30 \text { days }\end{array}$ & $\begin{array}{l}0.31 \\
1.91\end{array}$ & 1.13 & $\begin{array}{r}-1.98 \\
0.68\end{array}$ & -0.69 & $\begin{array}{l}0.44 \\
2.26\end{array}$ & 1.46 \\
\hline
\end{tabular}

* $N=7$; brackets: significant difference $P<0.05$ (Pair $t$ test).

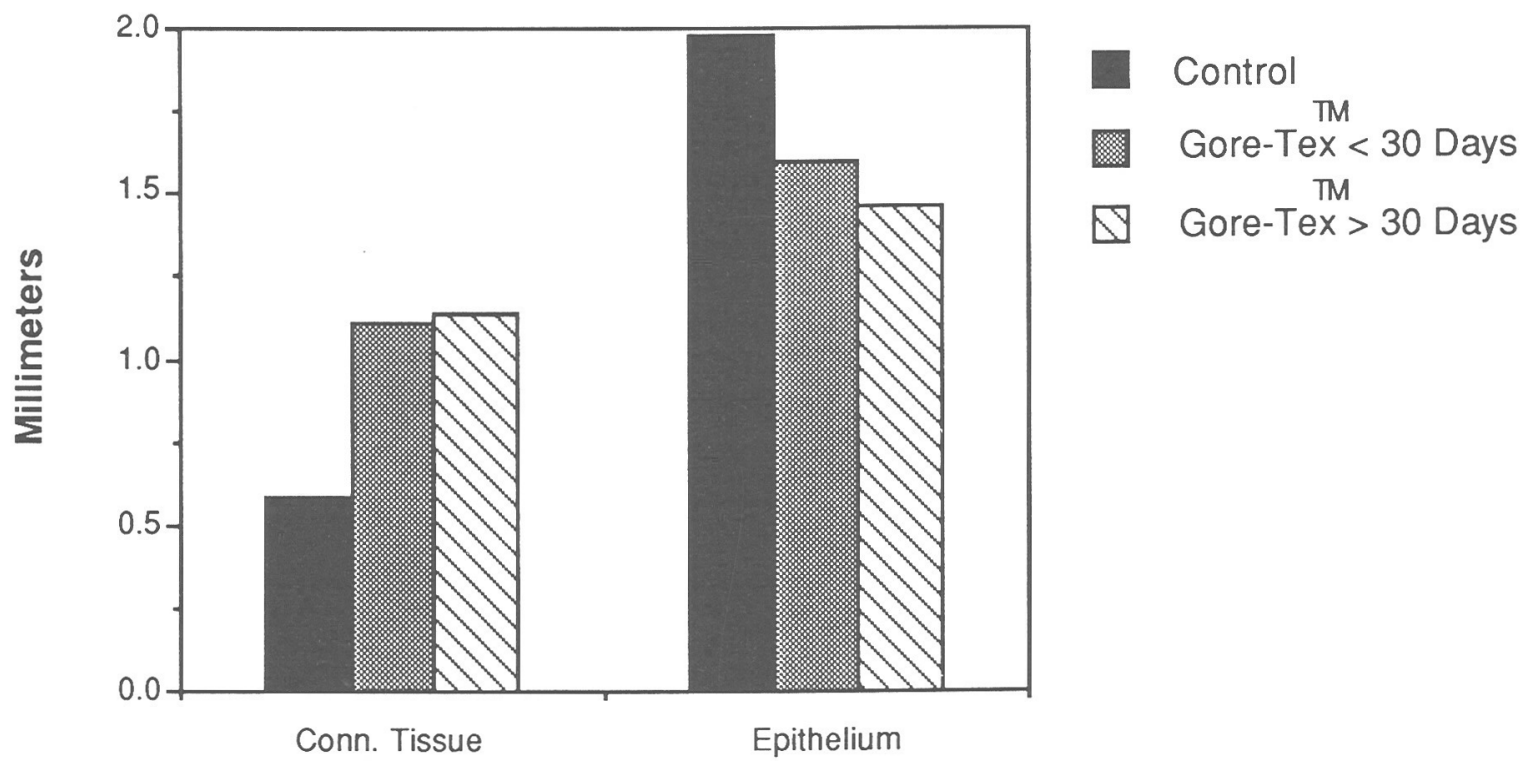

Figure 6. Connective tissue and epithelial regeneration after use of Gore-Tex periodontal material.

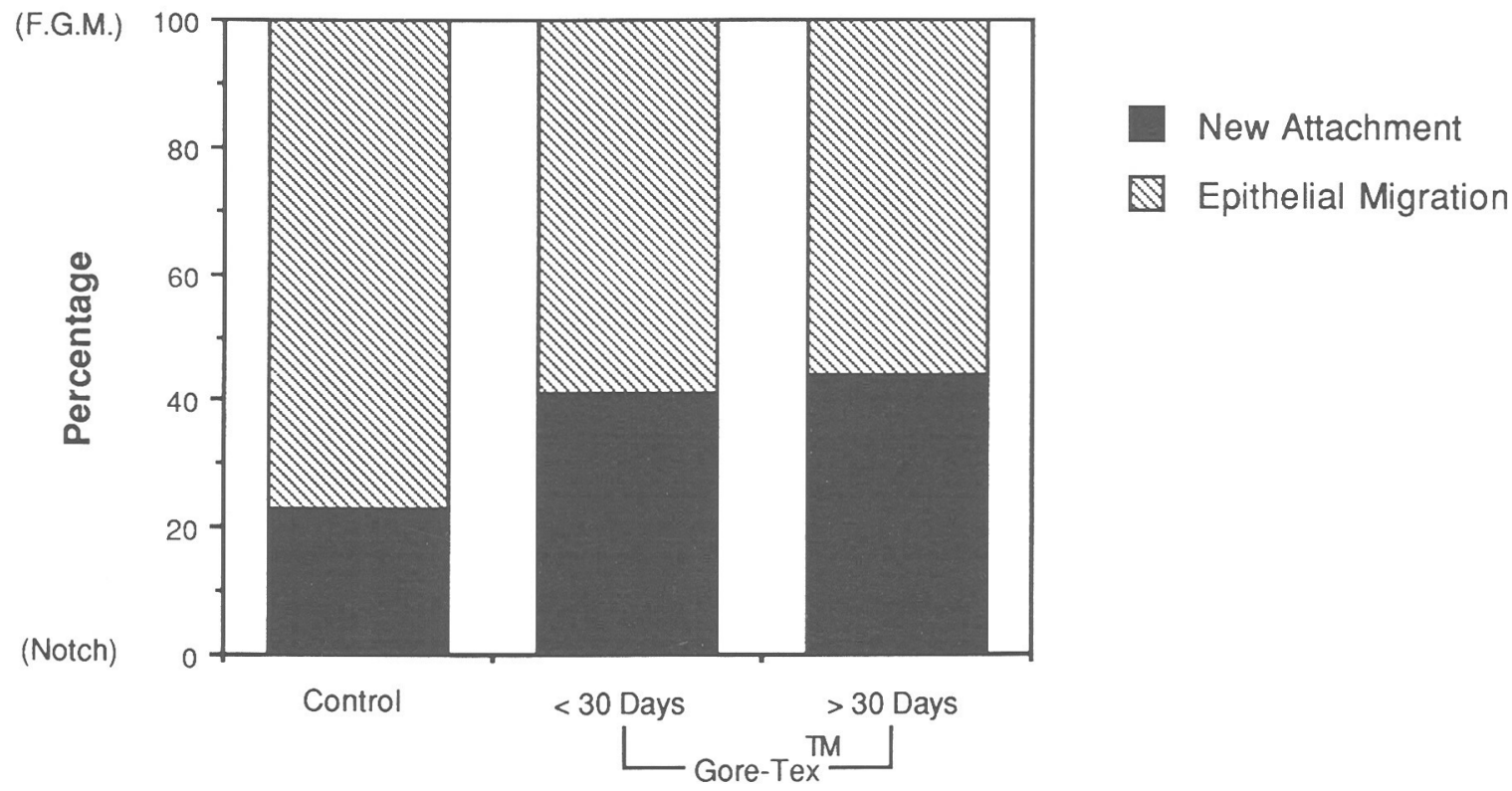

Figure 7. Percentage of new attachment and epithelial readaptation after use of Gore-Tex periodontal material. 
However, bone formation usually seems to lag behind the deposition of new cementum. Where this is not the case, ankylosis may develop. ${ }^{12}$

Furthermore, it has not been conclusively shown that other connective tissues lack the potential for promoting regeneration. ${ }^{14}$ Melcher et al. ${ }^{15}$ have suggested the possibility of cementum deposition as a consequence of proliferation originating from bone marrow cells.

The results of the present study indicate an overall positive result. However, the variability of results pointed out by Aukhil et al. ${ }^{11}$ is also reflected in the range of responses here. This is especially striking when the alveolar bone response is evaluated. Although bone formation was observed in some instances, the mean response was bone resorption. This could be attributed to the trauma of the surgical act, since it was also observed in the controls. However, during the three months of the experiment, such resorption was not repaired in its entirety.

The mean values of new connective tissue attachment reported in this study are greater than those reported by Aukhil et al. ${ }^{11}$ However, their ranges covered higher values than those in our population.

The promotion of cellular differentiation from progenitor cells of the periodontal ligament represents a viable approach to the achievement of new attachment in periodontal therapy. The Gore-Tex periodontal material appears to be effective in promoting "guided tissue regeneration."

\section{REFERENCES}

1. Polson, A.: The root surface and regeneration, present therapeutic limitations and future biologic potentials. J Clin Periodontol 13: $995,1986$.

2. Gottlow, J., Nyman, S., Lindhe, J., et al.: New attachment formation in the human periodontium by guided tissue regeneration. Case reports. J Clin Periodontol 13: 604, 1986.

3. Karring, T., Nyman, S., and Lindhe, J.: Healing following implantation of periodontitis affected roots into bone tissue. $J$ Clin Periodontol 7: 96, 1980.

4. Nyman, S., Karring, T., Lindhe, J., and Platen, S.: Healing following implantation of periodontitis-affected roots into gingival connective tissue. J Clin Periodontol 7: 394, 1980.

5. Nyman, S., Gottlow, J., Karring, T., and Lindhe, J.: The regenerative potential of the periodontal ligament. An experimental study in the monkey. J Clin Periodontol 9: 257, 1982.

6. Nyman, S., Lindhe, J., Karring, T., and Rylander, H.: New attachment following surgical treatment of human periodontal disease. J Clin Periodontol 9: 290, 1982.

7. Aukhil, I., Simpson, D. M., and Schaberg, T. V.: An experimental study of new attachment procedure in beagle dogs. $J$ Periodont Res 18: 643, 1983.

8. Gottlow, J., Nyman, S., Karring, T., and Lindhe, J.: New attachment formation as the result of controlled tissue regeneration. $J$ Clin Periodontol 11: 494, 1984.

9. Magnusson, I., Nyman, S., Karring, T., and Egelberg, J.: Connective tissue attachment formation following exclusion of gingival connective tissue and epithelium during healing. $J$ Periodont Res 20: 201, 1985.

10. Isidor, F., Karring, T., Nyman, S., and Lindhe, J.: The significance of coronal growth of periodontal ligament tissue for new attachment formation. J Clin Periodontol 13: 145, 1986.

11. Aukhil, I., Pettersson, E., and Suggs, C.: Guided tissue regeneration. An experimental procedure in Beagle dogs. J Periodontol 57: $727,1986$.

12. Card, S. J., Smith, B. A., Caffesse, R. G., et al:: New attachment following the surgical treatment of periodontitis in dogs (Abstr. No. 351). I.A.D.R. 1987.

13. Caffesse, R. G., Smith, B. A., Nasjleti, C. G., and Lopatin, D. E.: Cell proliferation after flap surgery, root conditioning and fibronectin application. J Periodontol 58: 661, 1987.

14. Heaney, T.: Inhibition of fibroblast attachment. J Clin Periodontol 13: 987, 1986.

15. Melcher, A., Cheong, T., Cox, J., Nemeth, E., and Shiga, A.: Synthesis of cementum-like tissue in vitro by cells cultured from bone: a light and electron microscope study. J Periodontol Res 21: $592,1986$.

Send reprint requests to: Dr. R. G. Caffesse, Department of Periodontics, The University of Texas Health Science Center, 6516 John Freeman, Houston, TX 77030. 